\title{
Reconstruction and Restoration of Main Facade and Wooden Ceilings of Hasan Basha Tahir Kuttab \& Sabil, Cairo-Egypt
}

\author{
Mahran F. Anwar \\ Conservation Department, Institute of Tourism, Hotel Management and Restoration, Alexandria, Egypt \\ Email: anwar_mahran@yahoo.com
}

How to cite this paper: Anwar, M.F. (2019) Reconstruction and Restoration of Main Facade and Wooden Ceilings of Hasan Basha Tahir Kuttab \& Sabil, Cairo-Egypt. World Journal of Engineering and Technology, 7, 175-192. https://doi.org/10.4236/wjet.2019.71012

Received: December 3, 2018

Accepted: February 11, 2019

Published: February 14, 2019

Copyright $\odot 2019$ by author(s) and Scientific Research Publishing Inc. This work is licensed under the Creative Commons Attribution International License (CC BY 4.0).

http://creativecommons.org/licenses/by/4.0/

\section{cc) (i) Open Access}

\begin{abstract}
The architectural complexes of Hasan Basha Tahir were suffering from many damages and deformation in different elements as load bearing walls, arches and wooden ceiling. Ground water, salt weathering, air pollution, biological colonization and environmental aspects were the main degradation factors which caused a lot of damage and deterioration phenomena in the complexes. Horizontal and vertical cracks, salts, loss of decorations, and featured dark of the stone surface were noticed at the complexes elements. In addition, the celling of the complex was in a very bad condition; it had lost a lot of decoration elements, cracking, soot deposition, insects' holes, and fungi growth. This research will discuss the various deterioration phenomena that have effect on the main building materials and cause the damages and discuss the general scientific methodology of the architectural and structural conservation project which was carried out.
\end{abstract}

\section{Keywords}

Architectural Complexes, Ottoman Period, Damages, Ceiling Construction, Bearing Wall, Conservation, Re-Construction

\section{Introduction}

\subsection{Historical and Architectural Background}

The mosque-Kutab \& Sabil of Hasan Pasha Tahir belonged to Ottoman period. It was built in 1809 ad-1224 h by Hasan pasha Tahir and his brother Abdin Bey Tahir in Sayyida Zaynab. The complexes take No. 210, located in the banks of Birkat al-Fil (elephant pond ${ }^{1}$ ), Port Said Street, Cairo.

1"Elephant pond was not a deep pond where stagnant water, but it was agricultural land flooded by the Nile every year at the time of the flood was irrigated from the Egyptian Gulf and after the drought of the land is exposed and cultivated winter crops". 


\section{Architecture elements of Sabil and Kuttab}

The main façade it is characterized by the main entrance, which contains two mastapa and a three-pronged orthodontic arc. The entrance is topped by a marble lintel carved with the foundation text of the mosque. The facade was deformed by the earthquake. It is characterized by excessive ornamentation. It represents a model of the beauty and development of the beautiful stone decoration in the Ayyubid and Mamluk buildings.

Window of Sabil is a local Style with one window, and a marble slab and window consist of metal sticks; behind its wooden veil, the top consists of Nested Stones its button above a stone bar by floral and geometric and identifies all by hexagonal style Gavetto. The wooden ceiling is decorated with the Ottoman decorations in a floral plantation of fruit plants. The decoration is made of oil paints. The floor is carefully decorated with marble tiles and behind sabil window there the Water basin made of one piece from marble (Figure 1(a), Figure $1(b))$.

Kuttab: It in above of Sabil and lake on out by tow windows in form ring horse arches style, based on wall from sides and on marble column in the middle and this windows filled by either italic Maymouni and wooden work with white glass.

Decorated structure: This façade is characterized by over-ornate decoration, where a huge collection of vegetal and geometric motifs was dug in the stone, which meticulously digs into the mind the beauty and beauty of the stone motifs in which the Ayyubid and Mamluk buildings were decorated (Figure 2(a)-(c)).

\subsection{Construction Systems}

Bearing walls construction: The facade was constructed with limestone bearing

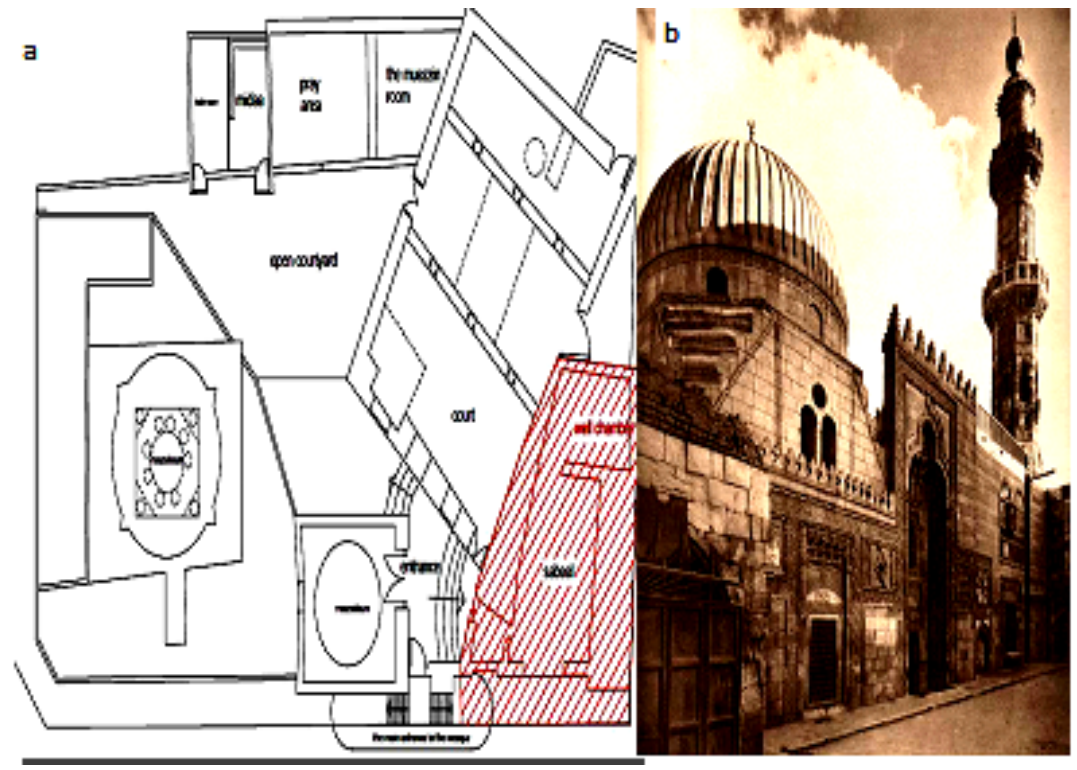

Figure 1. Kuttab \& Sabil of Hassan Taher Pasha, (a) the plane of Kuttab \& Sabil, (b) the façade of Kuttab \& Sabil before October quic.1992. 

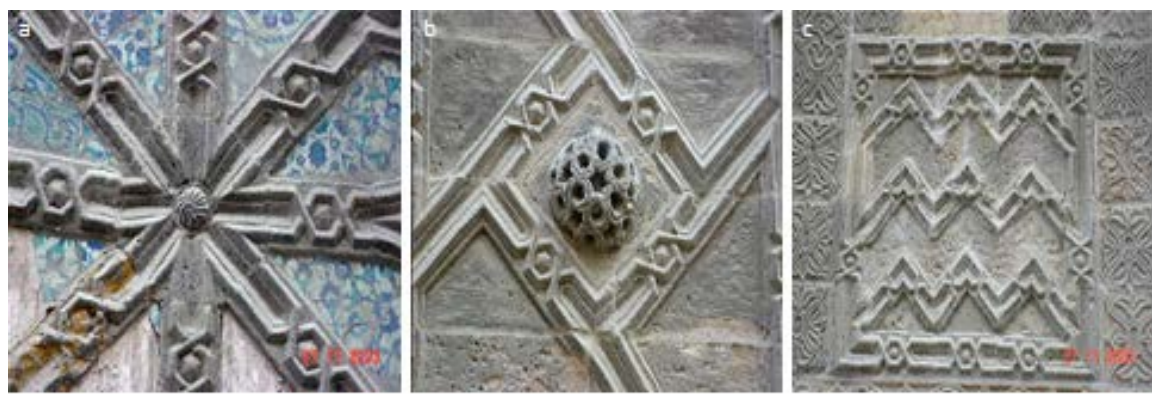

Figure 2. Stone decoration at the facade of Kuttab \& Sabil, (a) Repetitive frequency around the center one, (b) Vicious ball hard same block of engineering structures, (c) Broken Cavetto Lines (sevens \& eights) evidence of flexibility.

walls. This system is based on the continuity of the walls to ensure the regular distribution of the loads. Therefore, we notice that the openings are not increased by one third of the length of the wall in the horizontal plan. In addition, the thickness is gradually increased in the lower floors and strip foundations. In the direction of the forces-horizontally and vertically-that is, bending resistance, for example, of a horizontal beam is different from the bending resistance of a vertical beam, which is the result of the nature of the walls and that it is executed in the form of horizontal pillars overlapping in the horizontal direction and not overlapping in the vertical direction, such as wood, for example, as their properties change towards the natural fibers of wood.

Ceiling construction techniques: Ceiling as part of the decorations of this architectural Complex has some diversity in the context of the decoration and construction techniques. The construction and decoration techniques differ according to the wealth of the owner, talent of the craftsman and the function of the Complex. These factors affected the ceiling type of the complex; wood is the intended coverage of the flat or slanted surfaces of the ceiling; different sectors of the veins with 11 dimensions $10 \times 10 \mathrm{~cm}$ to wooden beams sectors of $30 \times 30 \mathrm{~cm}$ were used. Wooden beams (Baratim) Wooden blocks extending between the sides of the building have several labels such as squares and Almarbu'at, they are called "tide" (Figure 3). The Baratim settle on the stone walls, while the rest of the walls are built above the Baratim. Thus appear as if buried in the walls for the installation, these are placed at equal distances due to the number and size of the area needed to be covered, by the course of time, the Bartom consists either of a hull of a squared sector (with perpendicular angles) and sometimes rinsed edges in the central region or the body of a squared sector towards the wall and a semi-circular sector from the bottom in the middle, and convert from the square to the semi-circular work by stalactites (to convert the square to the circular). The confined spaces between each other either cover the decorated panels and demonstrate the highest in the unseen parts, the carpenter fix in the space between each Brtom perpendicular opposite beams to comprise the shallow grooves divided into regions of Marbu'at and crocodiles and fastens in the top of the Baratim and beams consisting of pallets and crocodiles by thin wooden boards 

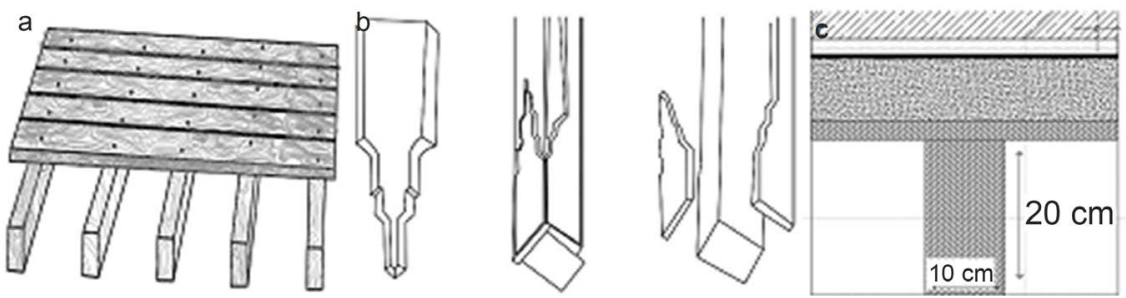

Figure 3. Ceiling Construction Techniques, (a) wooden beams at the ceiling of Sabil, (b) sole and sebah, (c) cross section of wooden beams (width $10 \mathrm{~cm} \times 20$ height).

bearing the decorative elements and there on the square (right-angled) from both sides of it an installed wooden decoration which is known to the workmen as the sole and extends by a tongue between the stalactites that helps in protecting the bottom of both sides of the Baratim from the effects of air on the decorations or it may be an installed one on the Baratim angles for a decorative purpose, on both sides of it there are wooden ornaments called "the swimmer", proving the hull sides of it In addition to the decorative form, it works to fill any holes between the Baratim and wooden pallets and crocodiles (Figure 4).

Complementary elements of wooden ceilings

1) Hernaúa: Known to the workmen by that name, which is a rectangular piece of wood placed between each two Brtom when, and fixed with nails, it hides behind the walls and the rest of it which is uncoated, and maintains the distance confined between the wood beams and the others.

2) Alqtronah: Which is fixed to the bottom of wooden planks with nails, and to be perpendicular to the wall to hide the Baratim overlap in the wall, and be a liaison between the wood beams, the Izar and Hernaúaat.

\section{Conservation State of the Sabil \& Kuttab}

\subsection{The Facade of the Sabil \& Kuttab}

Several weathering forms were identified and recorded at the façade of the Sabil \& Kuttab of Hassan Taher Pasha. The foundations were hidden below the layers of fill and indicate the poor condition of the general tendency of the structural elements starting from the base, indicating the positional crushing of the foundations and lower pillars. Partial collapse and serious tendencies in arches and vertical elements such as walls and columns in the facade were clearly noticed, mainly due to the dynamic factors (earthquake) which occurred on October 1992. The bearing walls under the influence of the wheel of vibration and horizontal pressures due to earthquakes send a range of wave shocks and have a mechanical effect on the strength of structural elements, causing partial and totally collapse because the building under the pressure of a sharp vibration wheel led to that each structural element takes an independent behavior according to its properties (Figure 5) [1]. Seismic performance is affected to any premises with two main factors soil properties that it is building, and earthquake waves depending on soil type and shape layers and their characteristics in terms of solidity and coherence, as well as seismic performance is affected by the properties 


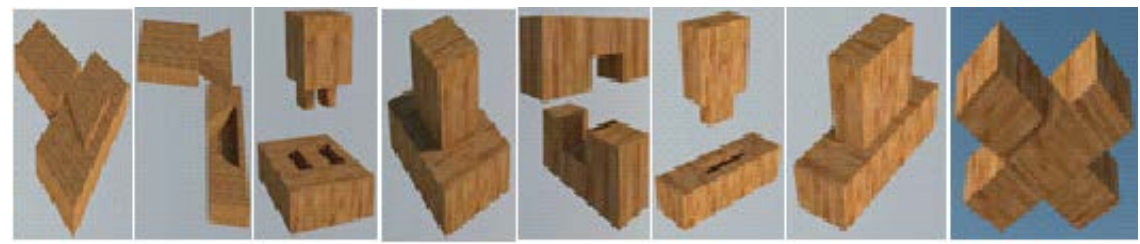

Figure 4. The wooden joints used in assembly and installation of wooden ceiling.
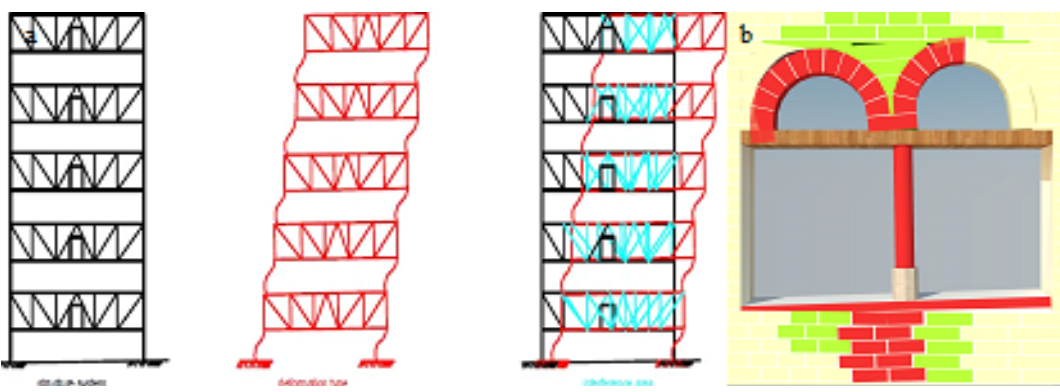

Figure 5. The bearing walls under the influence of the wheel of vibration and horizontal pressures due to earthquakes.

of the building itself, whether the underground or the tip above in terms of guiding a projected interfaces and type of construction in the building [2]. Tendencies and incline the marble column and fall off area of gravity and move the wooden pillow top of the crown. Many vertical, diagonal cracks in the walls as shown in which led to dangerous deterioration in the architectural elements like arches, gifts and threshold more cracks were found at top of the façade. The cracks at top of facade and at the end of facade are indicating to continuous wave movements. Vertical cracks generally indicate poorly bonded material that has, vertical cracks generally indicate to poorly bonded material that has lost its cohesion and is therefore weak. Black crust and soiling were coated the surfaces of Sebil and Kutab building materials resulting from atmospheric pollution from the center of Cairo (Figure 6). The main of stone deterioration of the façade results from combination of raised groundwater level and the capillary transport of salt laden water due to the actual level of humidity and its continuous mechanism. The pressure of salt crystallization enhances the growth and development of micro and macro fractures and consequently leads to granular disintegration, scales, spalling, flaking prevail inside and breaks up stone surface and also decrease the overall strength of the stone especially in the lower parts of the walls [3].

\subsection{The Wood Ceiling of the Sabil \& Kuttab}

Several weathering forms were identified and recorded at the celling of the Sabil \& Kuttab of Hassan Taher Pasha:

- Bending in the wooden beams and receding in the riding area on the walls (Figure 7).

- No Wooden Pillow bottom of beams which led to bad in distribution of loads in the headrest's areas. 


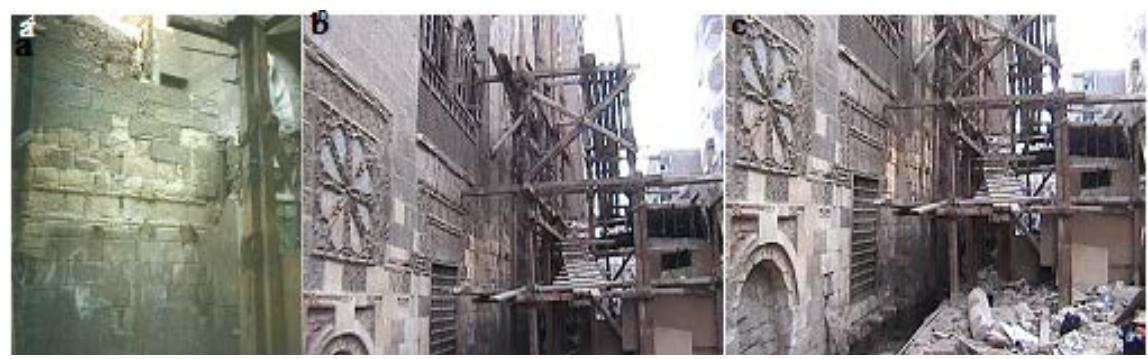

Figure 6. The deterioration aspects at the façade of the Sebil and Kuttab.

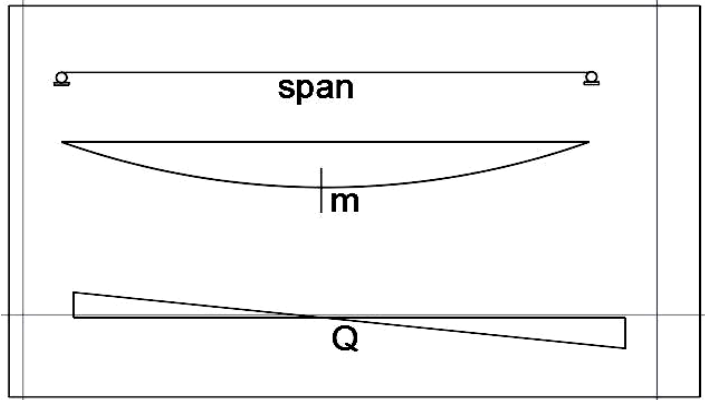

Figure 7. The kinds of binding occurred in the celieng of the complexes of Hasan Basha Tahir.

- The wood ceiling and its decorative paintings on the Sabil and Kuttab were in a very bad condition, which created by a combination of organic and inorganic materials. It had several different deterioration marks, as; warps, twists and irregular shape dry wood used in the ceilings, to shift mostly to curly plates wrapped wooden beams as a result of changes in temperatures and humidity daily, seasonally and annually, which lead to the separation of wood panels that carry layers of color, which lost large parts of them.

- Spread of cracks and deep cracks between wooden panels: that comprises the ceilings as well as the proliferation of these cracks in colorful layers above those panels.

- Colored material used in decoration had an occurred chromatic as color shift phenomenon of change as a result of chemical degradation resulting from the impact of heat and humidity and air pollution and the material became darker and lost its originality and beauty.

- The ceiling had been damaged and loss of many architectural elements as a result of biological attack.

- In addition to insects attack ceilings and caused tearing wood fiber with microorganisms and turned large parts of that to weak soft wood.

- All of this type of physical damage has had a direct impact in the collapse of these ceilings, especially with the continuous movement and collapse of the walls carrying them. All deterioration aspects shown in (Figure 8, Figure 9).

\section{Materials and Methods}

Since samples had to be collected for analysis, they were taken from selected 


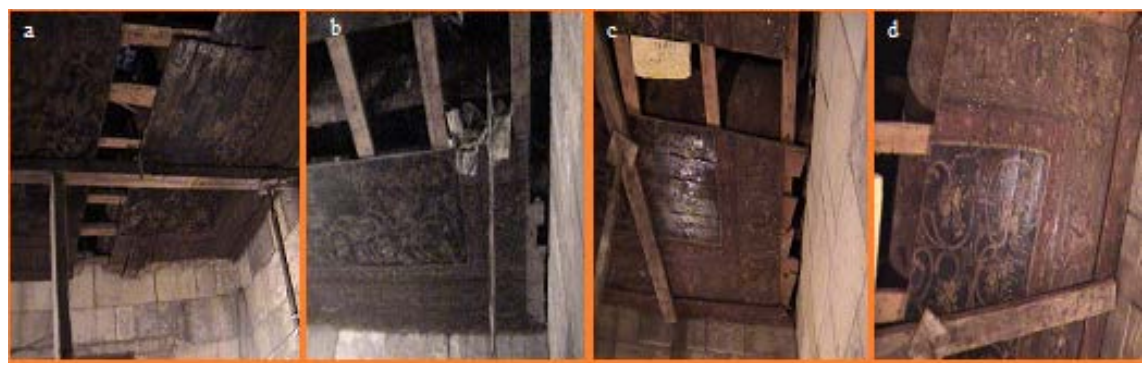

Figure 8. Shows the deterioration aspects of Sebil celling before decoding the wooden ceiling units.

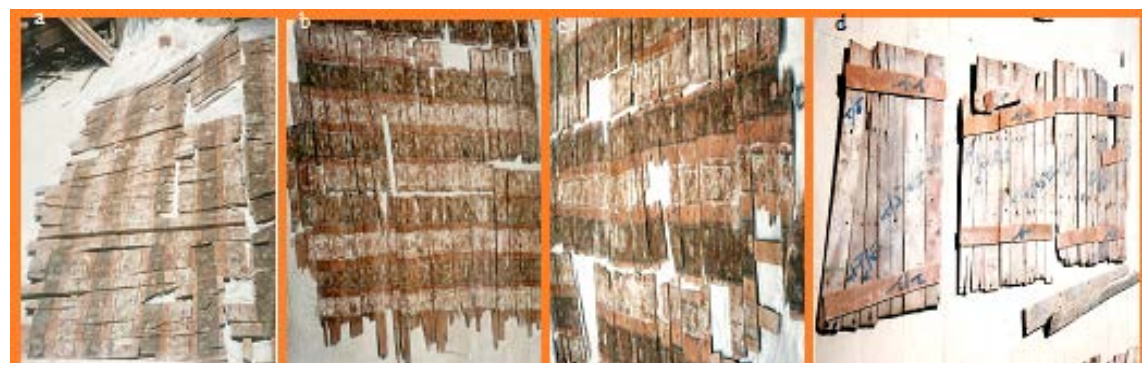

Figure 9. Shows the deterioration aspects of Sebil celling after decoding the wooden ceiling units.

areas that had no aesthetic value for future reconstruction or from deteriorated areas. Samples of limestone, mortar, residual salts and black rust were taken from the wall and wood samples, plaster and pigments were taken from the ceiling. All samples were analyzed to identify their composition and the products of the different weathering forms such as which types of salt were present. Petrographic thin sections were prepared and optically analyzed by using (Olympus BX51 TF japan) attached with digital camera under magnification $20 \times$ up to $40 \times$. The samples were analyzed using a JEOL JSM-6400 LV scanning electron microscope equipped with an Oxford Energy-Dispersive X-ray (EDX) system, detector model 6587. Scanning electron microscope micrographs were taken between magnifications $250 \times$ up to $3000 \times$. In order to be analyzed, the samples were coated with gold. The identification of the mineral composition of the samples was made by X-ray diffraction patterns, using a Philips X-ray PW 1840 diffractometer. The patterns were run with $\mathrm{Ni}$-filtered, $\mathrm{Cu}$ Ka radiation $(\lambda=$ $1.54056 \AA$ ) at $30 \mathrm{kV}$ and $10 \mathrm{~mA}$. The scanning was limited from $2 \theta=1$ to $2 \theta=$ $80^{\circ}$ range. Binding medium has been studied by Fourier transform infrared spectroscopy (FTIR). The samples were analyzed as $\mathrm{KBr}$ pellets by JASCO FT \IR-460 plus and the samples were examined between 4000 and $400 \mathrm{~cm}^{-1}$.

Cubic samples $(4 \times 4 \times 4 \mathrm{~cm})$ of limestone were taken from the deteriorated block from the inner wall of the Sabil facade to evaluate the physical properties (bulk density, porosity and water absorption) and mechanical properties (compressive strength), then dried at a temperature of $105^{\circ} \mathrm{C}$ until constant weight was achieved. Cubic samples $(2 \times 2 \times 2)$ of wood were taken from deteriorated wooden Barttium to evaluate the mechanical properties of wood (tensile, shear 
and compressive strength).

\section{Results and Discussion}

\subsection{Limestone Façade}

\subsubsection{Petrographic Study of Limestone}

Examination of thin sections of the limestone samples under polarized light microscope (Figure 10) displayed fine-grained calcite crystals, on top of iron oxides, clay minerals and numerous grains of quartz that were also found occurring as sub rounded to angular.

\subsubsection{SEM Examination}

The obtained results showed that there is a wide range of deterioration of limestone (Figure 11) such as; disintegration between calcite crystals, dissolution of calcite crystals and loss in the binding materials between grains by the effect of salts crystallization, small fissures and cracks, localized cavities. Microscopic investigation of the mortar from filling the Interior between stone walls samples used in Sabil \& Kuttab revealed deformation in mineral composition, the crystal edges and surface tissue and spaces between quartz, covering sodium chloride crystals for most samples of minerals composition (Figure 12).

\subsubsection{SEM-EDX Examination}

EDX analysis of altered limestone (Figure 13(a)) commonly consisted of Ca, S, $\mathrm{Si}, \mathrm{K}, \mathrm{Al}$ and $\mathrm{Fe}$. Considering the above results, it can be claimed that, the limestone in façade consists of calcite $\left(\mathrm{Ca} \mathrm{CO}_{3}\right)$, quartz $\left(\mathrm{SiO}_{2}\right)$, clay minerals and iron oxide. The analysis also revealed a high concentration of sulfate $\mathrm{S}$ which may be attributed to the crystallization of gypsum salts on the wall. EDX microanalysis of the mortar samples (Figure 13(b)) showed that $\mathrm{Ca}, \mathrm{Si}$ and $\mathrm{Fe}$ are the major ions contained, while $\mathrm{Mg}, \mathrm{S}, \mathrm{Cl}$ and $\mathrm{K}$ are secondary elements. Considering this result, it can be claimed that mortar between the blocks in the façade is lime mortar, which consists of calcite (lime) quartz (sand). EDX analysis of salt samples (Figure 13(c)) indicated that high concentration of chlorine $(\mathrm{Cl})$ which attributed to the crystallization of halite salt.

\subsubsection{Mineralogical Analysis by XRD}

XRD patterns of the limestone samples are given in (Figure 14), show that the sample consists essentially of calcite $\mathrm{CaCO}_{3}$, Quartz $\mathrm{SiO}_{2}$, Albite $\mathrm{NaAlSi}_{3} \mathrm{O}_{8}$ and traces of iron oxide.

\subsubsection{Physical and Mechanical Tests of Limestone Results}

The physical properties detected that the limestone of the facade is characterized by medium porosity $(5.46 \%)$, water absorption rate $(2.38 \%)$ and its consequent ability to absorb water with salt solution and this is the main cause of deterioration. The bulk density of the samples gives $\left(2.29 \mathrm{gm} / \mathrm{cm}^{3}\right)$ (Table 1). The mechanical properties were measured; the results showed that the strength of limestone in the facade characterized by poor mechanical characteristics (285 

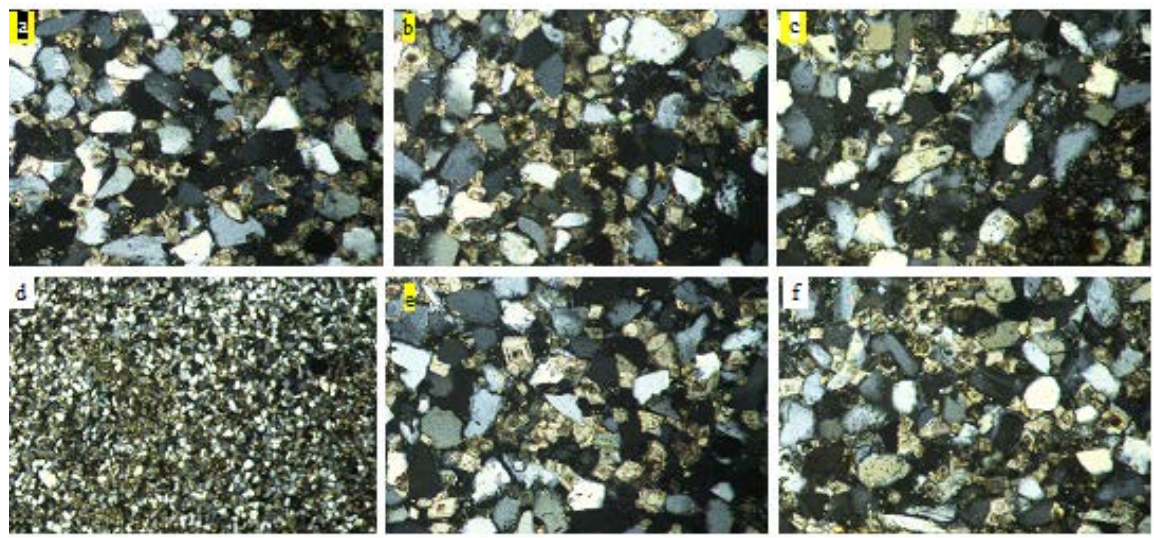

Figure 10. The examination of the limestone samples under polarized microscope, (a), (b) Fine grained calcite (micrite), (c) iron oxides, (d) numerous grains of quartz, (e) (f) fossils fragments.
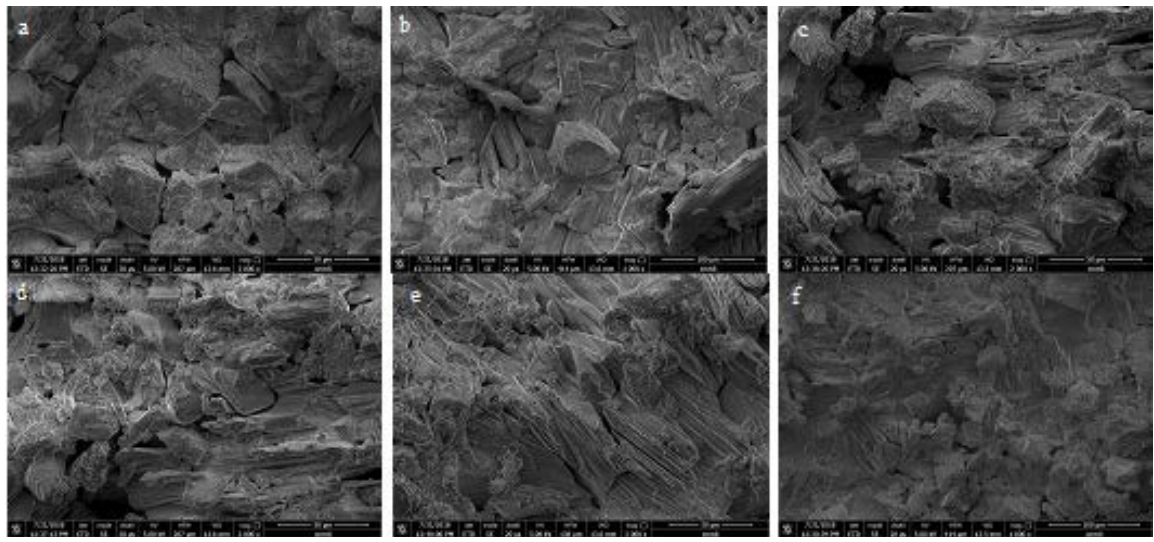

Figure 11. SEM micrograph of limestone sample from Hassan Taher Mosque.

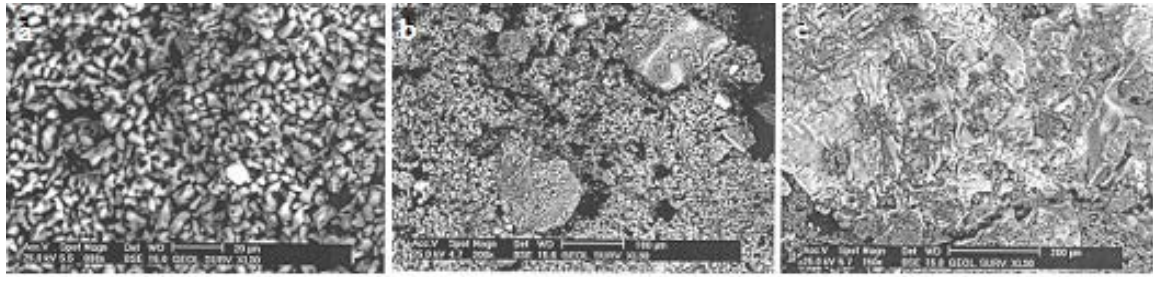

Figure 12. SEM images of mortar samples: (a) deformation in mineral Composition $(800 \times)$, (b) the crystal edges and surface tissue and spaces between quartz, (c) Covering sodium chloride crystals for most sample of metal composition.

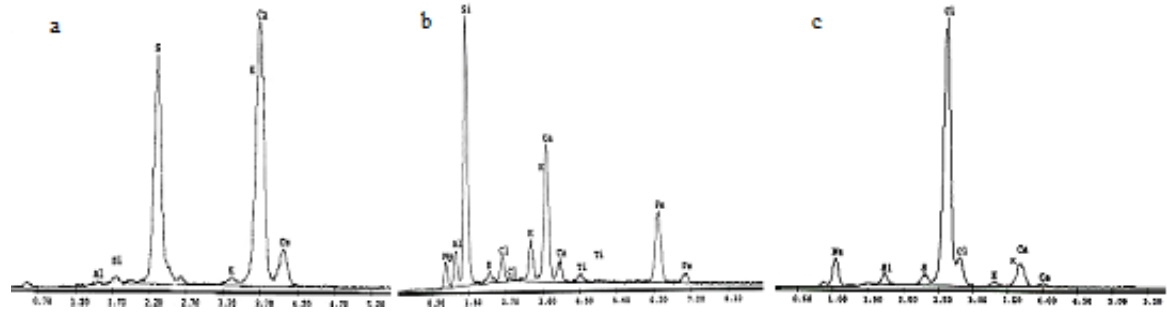

Figure 13. EDX Pattern of limestone, mortar and salt samples from Hassan Taher Mosque. 

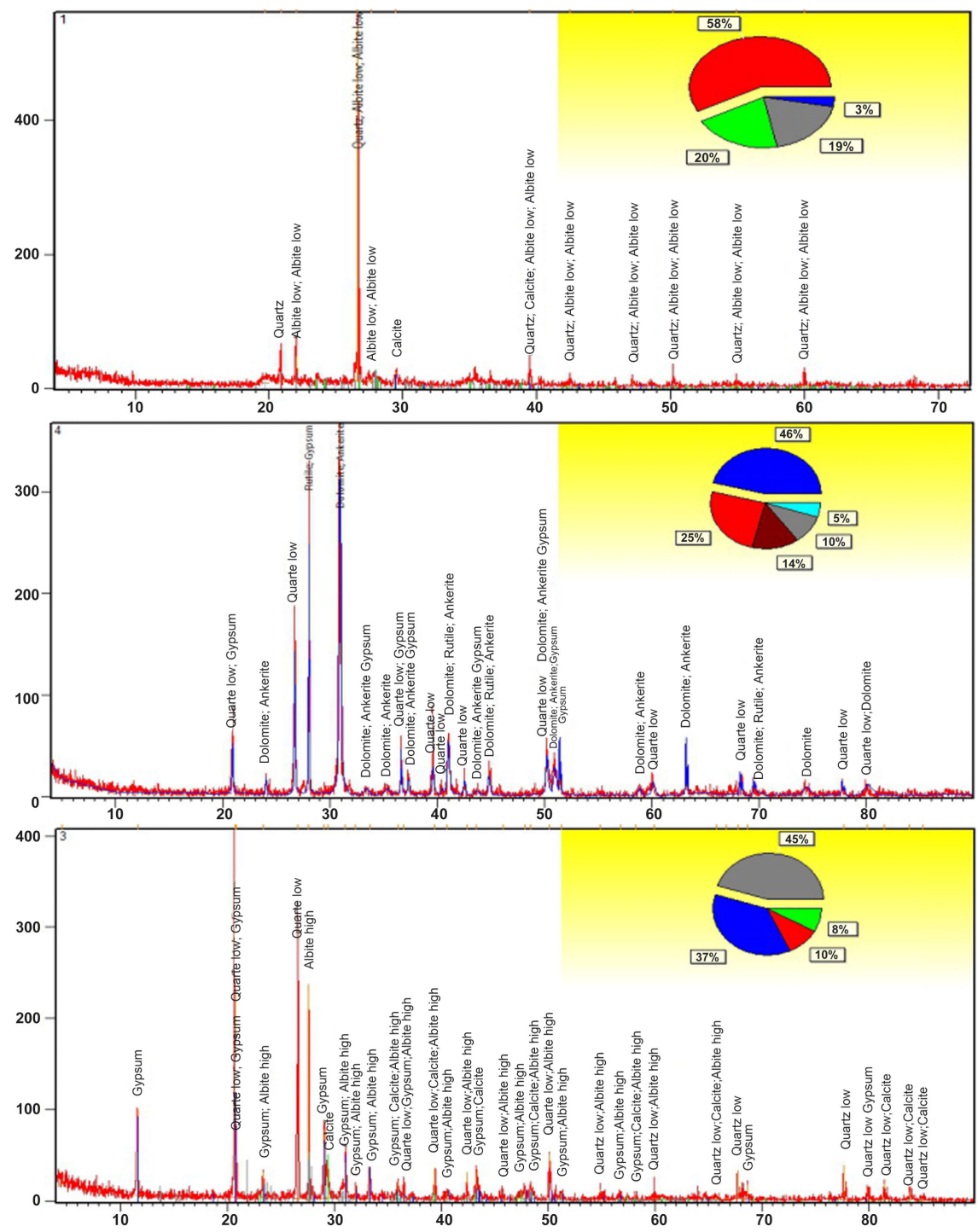

Figure 14. Patterns of XRD analysis of limestone samples, (a) foundation underground, (b) hard crust layer on stone surface, (c) internal filler point.

Table 1. Physical and mechanical properties of limestone.

\begin{tabular}{ccc}
\hline Physical \& Mechanical Properties & Untreated Samples \\
\hline Bulk density $\left(\mathrm{gm} / \mathrm{cm}^{3}\right)$ & \multicolumn{2}{c}{2.2908} \\
Water absorption (\%) & 2.3862 \\
Porosity (\%) & 5.4635 \\
& Dry & Wet \\
Compressive strength $\left(\mathrm{gm} / \mathrm{cm}^{2}\right)$ & 285 & 175
\end{tabular}

$\mathrm{kg} / \mathrm{cm}^{2}$ ) Dry and $175 \mathrm{~kg} / \mathrm{cm}^{2}$ Wet (Table 1 ). The changes of physical and mechanical properties of the stone were a result of weathering.

\subsubsection{Grouting Type \& Soil Type}

From the Results of test, we can classify to clay soil in top and sandy soil below it 
(Figure 15), from this identification we can use grouting with this spil without pressure all most

\subsection{Characterization of the Wooden Ceiling and Its Decoration}

The decorative motifs of wooden ceiling wear applied as follows: the wood panels were covered with ground layer and painted with paint layer with pigments.

\subsubsection{Ground Layer Results}

The elemental composition analysis carried by EDS of ground layer (Figure 16(a)), revealed that they were consisted of high amounts of calcium (Ca), Sulphur $(\mathrm{S})$ and iron $(\mathrm{Fe})$ with low amounts of zinc $(\mathrm{Zn})$, magnesium $(\mathrm{Mg})$, chlorine $(\mathrm{Cl})$ and Sodium $(\mathrm{Na})$. Considering this result, it can be claimed that, the ground layer consisting of mixture of lime, gypsum and low amount of zinc. The presence of $\mathrm{Mg}$ attributed to dolomitic limestone used in lime, chlorine attributed to crystallization of halite.

\subsubsection{Paint Layer}

Chemical of the pigments have been determined by SEM-EDS analysis, the
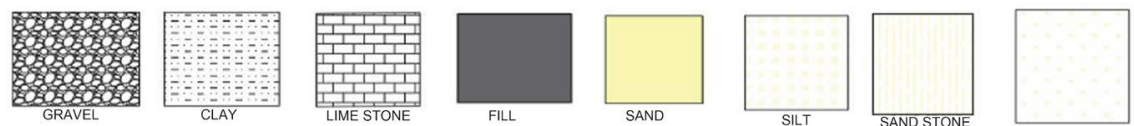

Figure 15. Grouting type \& soil type.
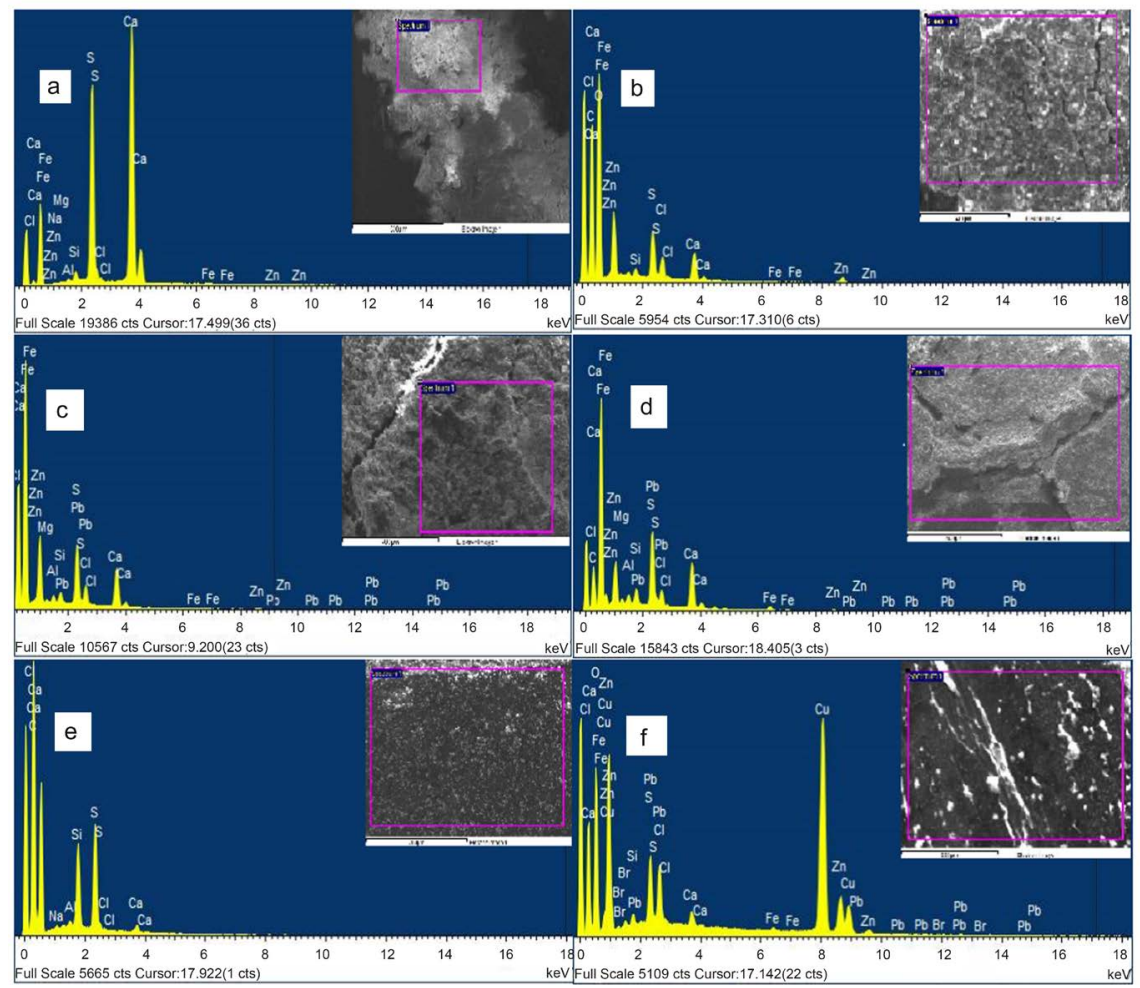

Figure 16. EDX patterns of paint layer; (a) Ground layer, (b) red paint, (c) brown paint, (d) yellow paint, (e) black paint, (f) gilded layer. 
mineralogical composition of pigments was not determined by XRD due to their low concentration in the thin films over priming layers.

Red pigment: The elemental composition analysis of the red sample (Figure 16(b)) indicates that, it is mainly composed of calcium (Ca), iron ( $\mathrm{Fe})$, zinc $(\mathrm{Zn})$, Sulphur $(\mathrm{S})$ and chlorine $(\mathrm{Cl})$. These results suggesting that, this colored paint could be prepared by iron oxide.

Brown pigment: The elemental composition analysis of the red painting surfaces (Figure 16(c)) indicate that it is mainly composed of iron (Fe), calcium $(\mathrm{Ca})$, Sulphur $(\mathrm{S})$, zinc $(\mathrm{Zn})$ and lead $(\mathrm{Pb})$. According these results, the brown paint was prepared by mixture of iron oxide and red lead (minium, $\mathrm{Pb}_{3} \mathrm{O}_{4}$ ).

Yellow pigment: The elemental composition analysis of the yellow paint (Figure 16(d)) indicate that it is mainly composed of iron (Fe), calcium, (Ca), Sulphur $(\mathrm{S})$, zinc $(\mathrm{Zn})$, lead $(\mathrm{Pb})$, magnesium $(\mathrm{Mg})$ and chlorine $(\mathrm{Cl})$ According these results, the yellow paint prepared by mixture of iron oxide.

Black pigment: The elemental composition analysis of the black paint (Figure 16(e)) indicate that it is mainly composed of, calcium, (Ca), carbon (C) sulphur (S). According these results, the yellow paint is carbon.

Gilded layer: Examination of the gilded layer in the ceiling (Figure 16(f)) indicate that it is mainly composed of Cupper $(\mathrm{Cu})$, Zink $(\mathrm{Zn})$, calcium (Ca), Sulphur (S). According to these results the gilded layers showed high percentage of copper and zinc indicating that the gilded layer may be brass, $\mathrm{Cu}-\mathrm{Zn}$ alloy.

\subsubsection{Fournier Transforms Infrared Spectroscopy (FTIR) Analysis}

The aim of this study is to identify organic binders in used as an intermediary. Sample from the red pigment was analyzed to identify the binders used with these pigments. The results were compared with standard samples of both animal glue and Arabic gum. Results showed that the tested samples have a high proportion of animal glue (Figure 17).

\subsubsection{Mechanical Properties of Wood Results}

This part is aimed to outline and discuss the measured mechanical properties of the wood samples the wood celling. Compressive strength (Figure 18(a)), tensile strength (Figure 18(b)) and shear strength (Figure 18(c)) are presented in Table 2.

\section{Restoration Work}

\subsection{The Restoration Work in the Ceiling}

\section{- Decomposition of wooden ceilings}

- The different elements of the ceilings were deconstructed as one unit with carful and assembled according to the technical specifications, after recording their sectors and the structural system for them on drawings with a suitable scale to restore the object to its original after restoration and reinforcement.

- Make a layer of foam panels on top of the decorated ceiling. 
Table 2. Mechanical properties of wood samples from wood celling.

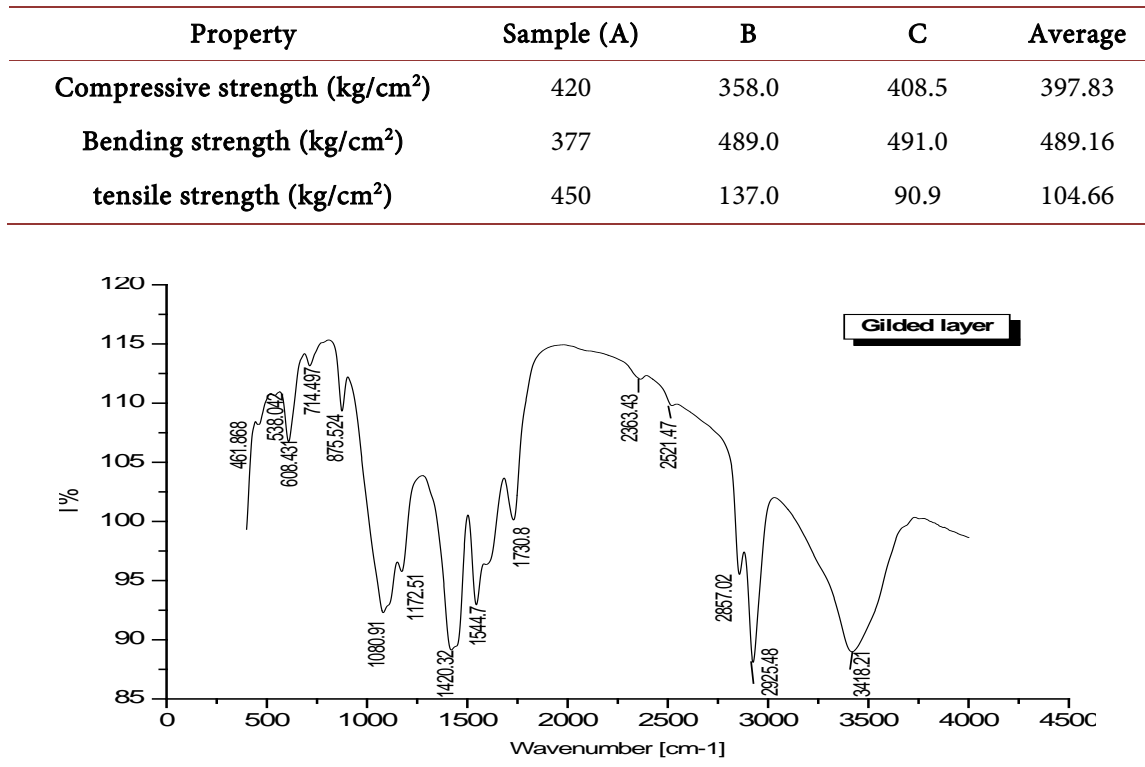

Figure 17. FTIR patern of red pigment.
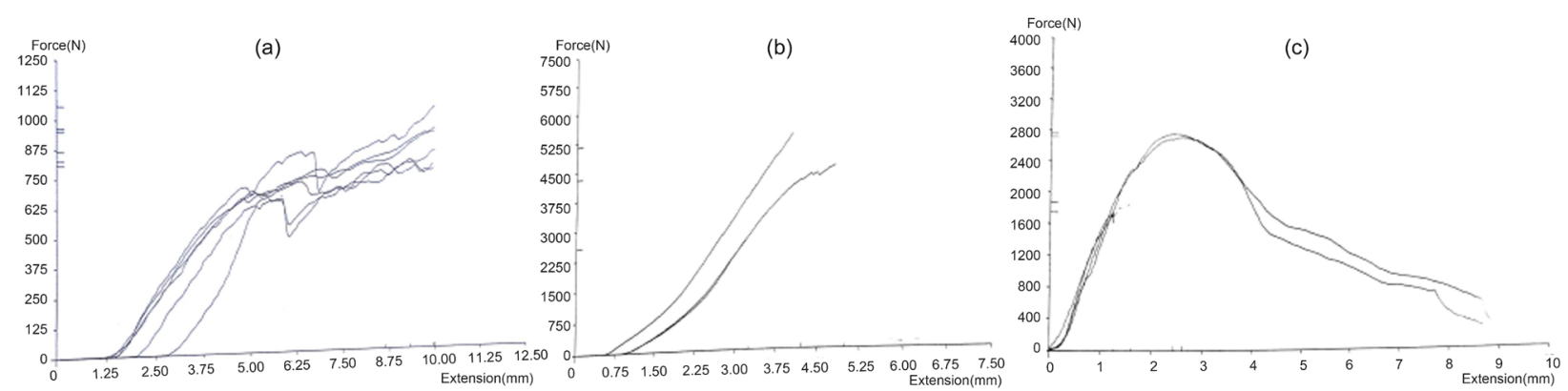

Figure 18. Mechanical testing of wood sample.

- Installation of wooden beams $(8 \times 6)$ inch down and top of the ceiling perpendicular to the direction of the ceiling sections and are connected by Stainless nails.

\section{- Reconstruction of wood ceiling}

- The flat ceilings consist of a group of wood beams based on the walls according to the distance between the walls and then come a vertical layer of wood panels (Figure 19).

- In the reconstruction, wooden beams added on the walls so that they can distribute loads along the wall (Figure 20).

- Construction filling layers and the necessary tendencies for water drainage.

- Cleaning

- Mechanical cleaning: This method is implemented by using multiple types of Brushes with soft hairs to remove dust and use medical and metal scalpels edges to remove salts and dust layered roofs colored glue. It was also using electrical appliances that push or pull to dust and damage output. And these stages must be done very carefully so as not to cause damage to photographic layers. 


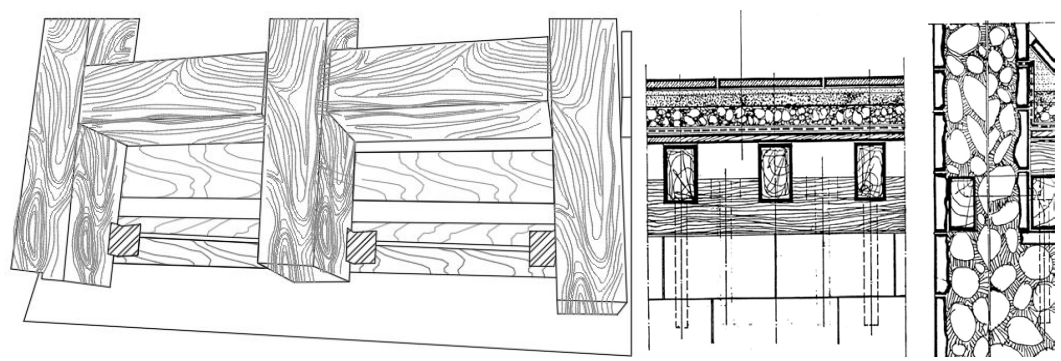

Figure 19. Show detailed section of wood beams and wood plates Panel when re-construction wood ceiling.

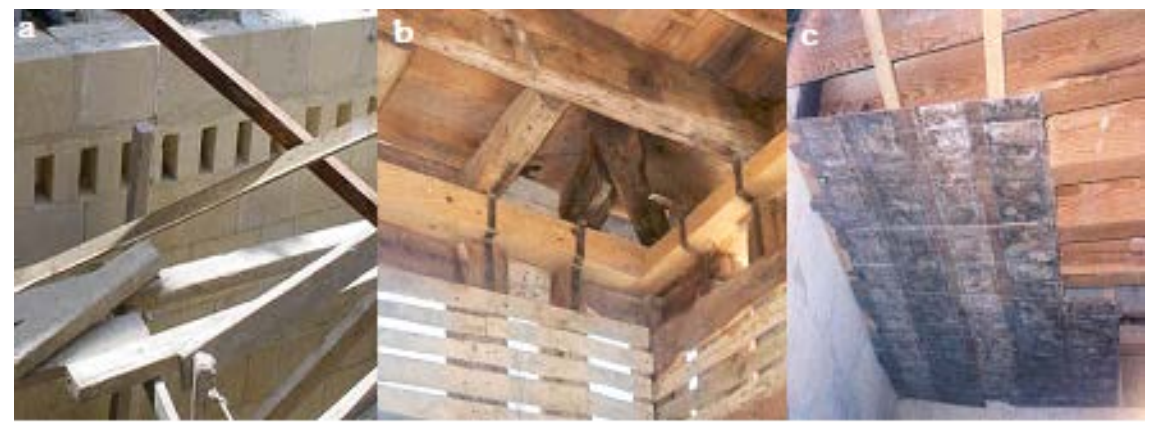

Figure 20. reconstruction and commplition technique of wooden painted piceces at the celieng.

- Chemical cleaning: This method relies on using different detergents and organic solvents special if mechanical cleaning methods have not succeeded in removing some of the outputs of the damage. Since organic solvents used to remove products of organic damage like drops of grease, fats and oils and residues of bird and microorganism, the following organic solvents has good success in removing this damaged outputs, Tetralene, Ethyl alcohol mixed with acetone and neutral Soap. We do not use water in clean-up operations for the previous test results proved that the colored material used in this ceiling is influenced by water as it mixed with animal glue substance.

- Treatment of wooden ceilings from remnants of biological outputs

- Possible test many deadly pesticides to microorganisms and insects or limiting their activity over a long period of time. Experience has shown that pesticide which consists of penta sodium chlorophenol came good results in reducing the severity of insect insects such as termites and fungi timber pesticide in acetone was used in concentrations ranging between 30\% and 40\% wood panels were sprayed and colored layers that Consist Of this ceiling in this solution.

- Filling gaps

- Either the spending gaps in the ceiling were filled with a paste consisting of fine powder of wood material mixed with Paraloid B.72 dissolved in acetone by concentration of $10 \%$ as a proportion of the pesticides were added and last entomological innate components of this Putty (Figure 21).

\section{- Consolidation}




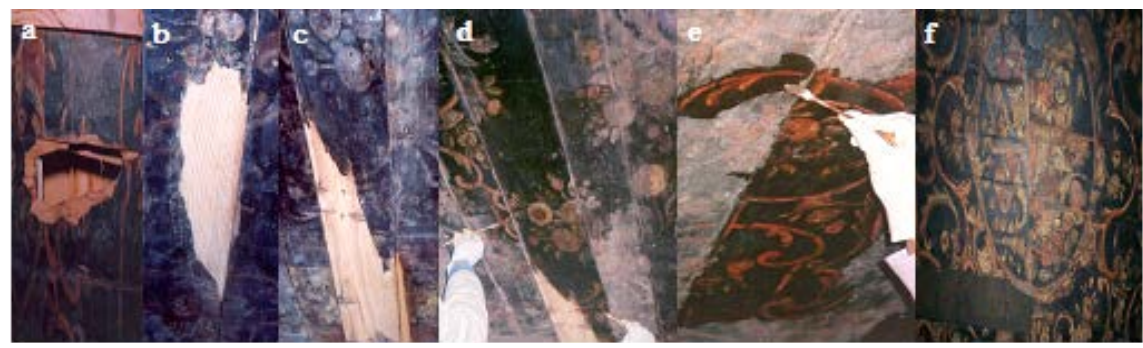

Figure 21. fine restoration work of painted wood at the celieng of sebil.

- Microscopic analysis results showed that most of the wood panels and the overlying colored layers in a severe case of weakness and incoherence. To strengthen these panels and those layers chemically using modern chemical polymers that are suitable for such cases has been tested many polymers such as polymerized vinyl acetate, caltone and area gal all which were Acrylic polymers, but they did not give good results (Figure 22).

- So, we turned to the use of Paraloid B.72 is a Poly-methyl methacrylate acrylic material which gave good results in treatment where the melting Polymer in acetone and get a homogeneous solution concentration $3 \%$ used a spray Spraying several times to colored layers as well as wood panels that consist of the Ceilings.

- Experience has shown that this Polymer resists the effects of heat and humidity and does not change color over time has proven that microorganisms can devour thin protective made this colorful substrates and wood panels prior to that was a former exterminator for limiting the gravity of these objects to this solution during treatment.

\subsection{Reconstruction of Facade of Sabil \& Kuttab}

The dismantling and reconstruction operations were an exceptional solution to the extreme necessity, especially with the structural and architectural deterioration due to the various soil problems on which the building was built. Therefore, all measures and precautions were taken to ensure that the components that were decomposed according to their Original location. The Reconstruction process was carried out as follows.

- Disassembly \& reassembly

- Conduct an integrated and scientific study to determine the current status of the interface elements.

- The numbering system for each piece is determined exactly the exact position and sign this numbering on drawings, and the classification tables for the numbered pieces were made (Figure 23).

- The monitoring work was carried out by a surveying system to determine the directions and to monitor the elevations necessary to ensure that the pieces were reconstructed in their original positions and directions.

- Determine the relationships between the numbered pieces and recording on drawing works to ensure the reconstruction process [4]. 


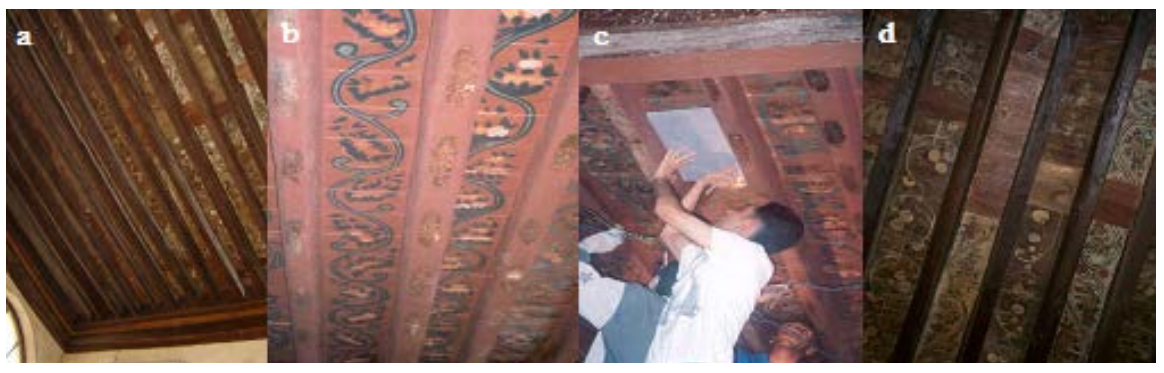

Figure 22. restoration worck at the celieng of Kutab.

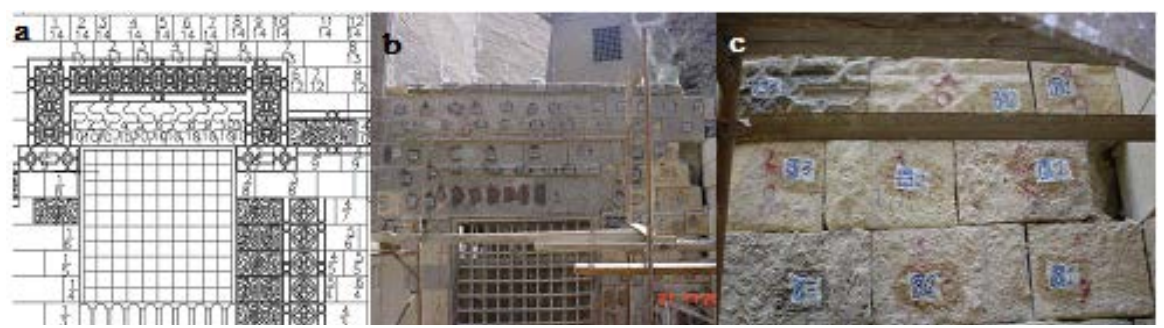

Figure 23. Numbering process for Façade elements on drawings and indicated in current position.

- The disassembled Pieces were placed in prepared area in a logical sequence to facilitate the re-sorting and assembly with the appropriate environmental suitability to provide appropriate weather conditions.

- Dismantling the column of the upper Kuttab

- Protection around the perimeter of the column.

- Before the disassembly of the column, the field monitoring work was carried out by total station.

- The column, base and crown were wrapped with polyethylene and assembled on site in wooden boxes designed for this purpose.

- Dismantling the arch of the upper Kuttab

- Prepare casting and negatives for formation elements.

- Numbering system for arch elements as stones and key stone.

- Placed dissembled pieces according to the logical order of the construction units of the arch.

- Reconstruction of main façade

- Construction begins to reverse disassembly work from bottom to top of the last recorded number on sheets of registration (Figure 24).

- Reconstruction using the same quality mortar and same recorded dimensions on registration sheets.

- The internal filler consist of breaking new stone free of salts according to the original mixtures or those selected after testing.

- The column are the elements that carry the forces resulting from the ceilings and arch in building Sabil \& Kuttab when reconstructing, the balance of these columns must be adjusted based on monitoring system by the total station. Considering the central pressure forces are the main loads applied to these columns so as to ensure that stress stresses are among the permissible values 
for carrying buildings, also the wooden pillow was replaced which are usually a middle stage between the leg of arch and crown of column for the importance of its structural role in the reduction of loads and absorption of vibrations (Figure 25).

- The arch is the ceiling-mounted element that is distributed to the load from the ceiling on columns and side bearing walls to reach the bearing soil. Depending on the shape of the arch in resistance to pressure stresses generated by the horizontal ceiling loads applied to the arch, supporting the end of arches to provide stability and horizontal push resistance. Because the crown was separated from the shaft cylinder, an iron-beam was attached between the end of the upper column and the crown, to making the largest points to resist horizontal forces.

- A final finishes and repointing using soft mortar according to original chemical composition and enhanced in its properties as shown in Table 3.

\section{Conclusion}

The architectural complex of Hassan Pasha Taher is characterized by overlapping between the architectural and human functions and must be restored to play its role in the development of the surrounding society, so this paper refers to considering the function of the building after restoration, structural interference in building elements and the difficulty of structural separation between elements. The paper concerned the necessity of improving the materials used in

Table 3. Mechanical tests of proposed samples Mortar application of reconstruction of some structural elements.

\begin{tabular}{|c|c|c|c|c|c|c|c|c|}
\hline \multirow[t]{2}{*}{ No. } & \multicolumn{4}{|c|}{ Sample Composition } & \multicolumn{2}{|c|}{$\begin{array}{c}\text { Compressive } \\
\text { Strength } \mathrm{Kg} / \mathrm{cm}^{2}\end{array}$} & \multirow{2}{*}{$\begin{array}{c}\text { Bending } \\
\text { Strength } \\
\mathrm{Kg} / \mathrm{cm}^{2}\end{array}$} & \multirow[t]{2}{*}{ Shrinkage \% } \\
\hline & Homra & Sand & Qosrmil & Lime & Dry & Wet & & \\
\hline A & - & - & 2 & 4 & 2.17 & 1.5 & 6.2 & 8.2 \\
\hline $\mathrm{B}$ & 1 & 3 & - & 4 & 8.4 & 5.3 & 7.6 & 5 \\
\hline $\mathrm{C}$ & 1 & - & 3 & 2 & 3.1 & 2 & 6 & 7.1 \\
\hline \multirow[t]{2}{*}{$\mathrm{D}$} & - & - & 2 & 3 & 2.4 & 1.8 & 4.6 & 6.1 \\
\hline & 2 & - & 2 & 2 & 7.9 & 5.7 & 7 & 7.1 \\
\hline
\end{tabular}

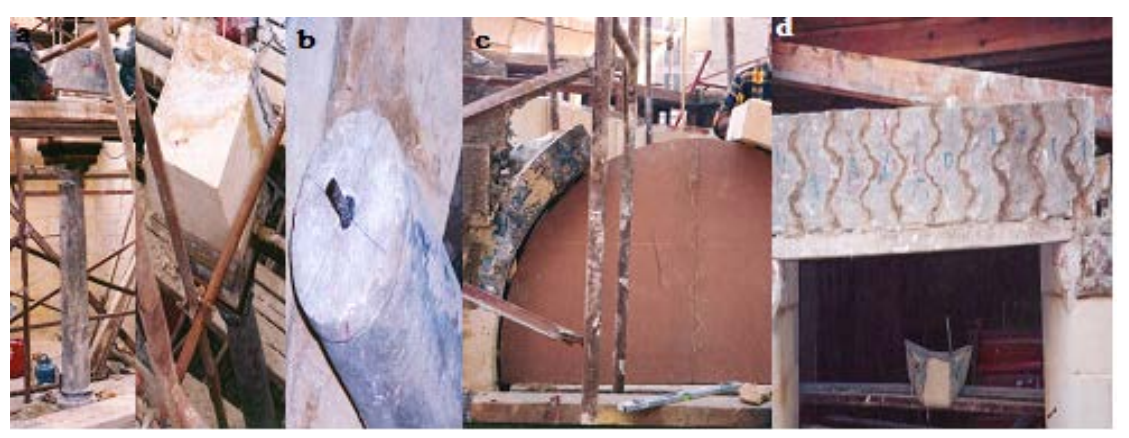

Figure 24. Reconstruction work of the façade. 


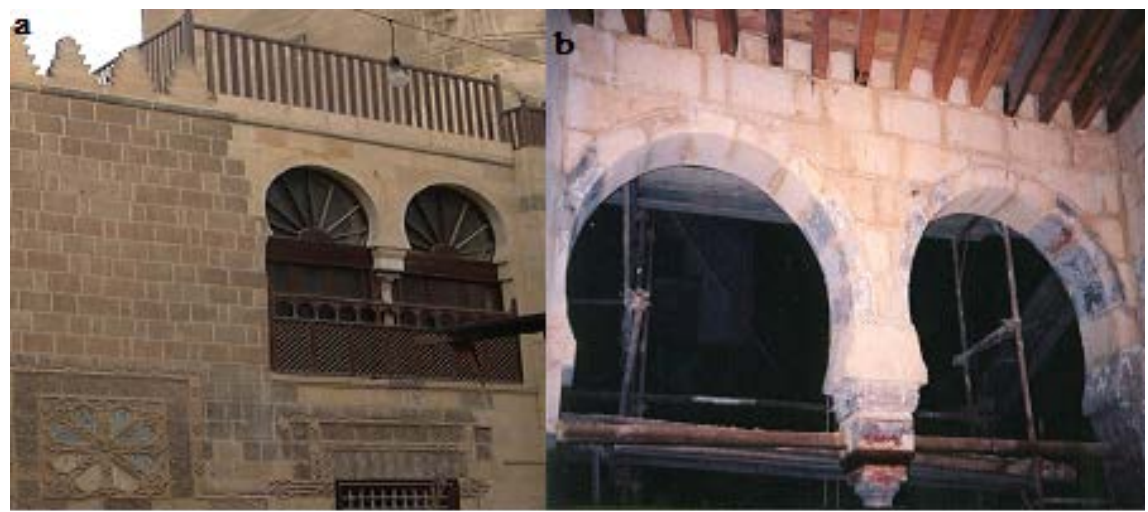

Figure 25. The Sabil and Kuttab of Hassan Taher after restoration.

the restoration process and their homogeneity with the original materials, wood from complex and sensitive materials in the process of restoration, especially when the varied structural and decorative roles, the completion of the facades or ceilings was characterized by a clear distinction between the original and completed parts. The restoration of façade and ceilings of kuttab and Sabil of the architectural Complex of Hassan Pasha Taher start with restore the vitality and stability of the structural elements followed by the reconstruction of the architectural formation and ended with the technical restoration of fine elements.

\section{Conflicts of Interest}

The author declares no conflicts of interest regarding the publication of this paper.

\section{References}

[1] Grfford and Partners The Proposal for the Stitching. American University, Cairo.

[2] Fellden, B. (2003) Conservation of Historic Buildings. 3rd Edition, Architectural Press, Oxford.

[3] Abd El-Tawab, N. and Mahran, A.F. (2015) Restoration and Preservation of Artistic Elements Applied on Islamic Architectural Facade of Shahin Agha Sebil, Cairo, Egypt. International Journal of Conservation Science, 6, 63-78.

[4] Dienter, M. Planning and Executing Anasthyosis of Stone Building, in Conversation and Archaeological Excavation Iccrom, Rome. 